\title{
O PAPEL DAS NOÇÕES DE CAUSAÇÃO INTERNA E CONTROLE NA REPRESENTAÇÃO DOS VERBOS DINÂMICOS MONOARGUMENTAIS
}

\section{THE ROLE OF THE NOTIONS OF INTERNAL CAUSATION AND CONTROL IN THE REPRESENTATION OF DYNAMIC MONOARGUMENTAL VERBS}

\author{
Pablo Nunes Ribeiro \\ Universidade Federal de Santa Maria \\ Santa Maria, Rio Grande do Sul, Brasil
}

RESUMO: Este artigo discute o papel das noções de causação interna e controle na representação léxicoconceitual de algumas subclasses de verbos dinâmicos monoargumentais, como os verbos de modo de movimento (p. ex., correr, rolar), de processos corporais (p. ex., rir, espirrar) e de emissão (p. ex., chiar, apitar). Os objetivos são analisar como essas propriedades determinam a participação desses verbos no processo de causativização e propor uma maneira de representá-las na estrutura conceitual desses predicados, sob a luz da Semântica Conceitual (JACKENDOFF, 1983; 1990; 2002). Para tanto, são examinados alguns problemas da proposta de Jackendoff (1990) para o tratamento dos verbos de modo de movimento, de modo a mostrar que o autor não dá conta do comportamento desses verbos em relação à causativização. São discutidas também análises clássicas das noções de controle, causação interna e eventos acionais na semântica lexical, que servem como base para a proposta apresentada neste trabalho. A hipótese defendida é a de que a distinção entre os predicados primitivos MOVE e ACT, através dos traços de controle e causação interna, é crucial para que se possa representar adequadamente a estrutura léxico-conceitual das subclasses de verbos dinâmicos monoargumentais e dar conta de sua participação ou não na causativização.

PALAVRAS-CHAVE: Verbos dinâmicos monoargumentais; Controle; Causação interna; Causativização; Semântica conceitual.

ABSTRACT: This paper discusses the role of the notions of internal causation and control in the lexical-conceptual representation of some subclasses of dynamic 
monoargumental verbs, such as the verbs of manner of motion (e.g. run, roll), bodily processes (e.g. laugh, sneeze) and emission (e.g. sizzle, whistle). The goals are analyzing how these properties determine the participation of these verbs in causativity processes and defining a way to represent these properties in the conceptual structure of these predicates, under the light of Conceptual Semantics (JACKENDOFF, 1983; 1990; 2002). For this purpose, we examine some issues of Jackendoff (1990)'s proposal for the treatment of manner of motion verbs in English, with the aim of showing that the author's analysis does not account for these verbs' grammatical behavior regarding the causativization process. We also discuss some classical analyses of the notions of control, internal causation and actions in lexical semantics, which serve as a basis for the proposal presented in this paper. The hypothesis we defend is that a distinction between the primitive predicates MOVE and ACT, by means of control and internal causation features, is crucial for adequately representing the lexicalconceptual structure of each subclass of dynamic monoargumental verbs and account for their participation or not in causativization.

KEYWORDS: Dynamic monoargumental verbs; Control; Internal causation; Causativization; Conceptual semantics. 


\section{INTRODUÇÃO}

Neste artigo discutirei o papel das noções de causação interna e controle na representação léxico-conceitual de diferentes classes de verbos dinâmicos monoargumentais no português brasileiro, como os verbos de modo de movimento (p. ex., correr, rolar, pular), de processos corporais (p. ex., rir, espirrar, dormir) e de emissão (p. ex., chiar, apitar, soar). Os objetivos são: (I) analisar como essas propriedades determinam a participação desses verbos em processos de causativização e (II) propor uma maneira de representá-las na estrutura conceitual desses predicados, sob a luz da Semântica Conceitual. ${ }^{1}$

Tradicionalmente, são considerados verbos de modo de movimento aqueles que denotam a maneira como o participante se movimenta, sem acarretar o seu deslocamento ao longo de uma trajetória (cf. LEVIN, 1993; LEVIN; RAPPAPORT HOVAV, 1998; entre outros). Um fato bastante conhecido na literatura, desde Levin (1993) e Levin \& Rappaport Hovav (1995), é o de que os verbos de modo de movimento da classe de correr não permitem a realização de uma variante causativa - por esse motivo, são considerados como inergativos -, ao passo que os verbos de modo de movimento do tipo de rolar possibilitam essa construção - sendo considerados, assim, inacusativos -, como ilustram os exemplos abaixo.
a. A bola rolou.
b. A roleta girou.
c. O jogador rolou a bola.
d. O menino girou a roleta.

(2) a. Paulo correu.

b. A garrafa flutuou.

c. *Ana correu Paulo.

d. *O pescador flutuou a garrafa.

Os verbos de processos corporais, grosso modo, são aqueles que envolvem processos relacionados ao corpo de participantes animados, os quais não são necessariamente controlados por esses participantes (cf. LEVIN, 1993). São representantes típicos dessa classe verbos como respirar, dormir, espirrar, rir,

\footnotetext{
${ }^{1}$ A Semântica Conceitual é uma abordagem formal para o estudo do significado nas línguas naturais proposta e desenvolvida por Ray Jackendoff essencialmente em seus livros Semantics and Cognition (1983), Semantic Structures (1990) e Foundations of Language (2002). Trata-se de uma teoria fundamentada na ideia de que a descrição do significado envolve a descrição de representações mentais, o que a define como uma teoria mentalista. Dessa maneira, o objetivo fundamental desta teoria semântica é descrever e explicar a maneira como os falantes expressam suas ideias e seu conhecimento de mundo por meio de enunciados linguísticos, a partir de conceitos mentalmente codificados.
} 
etc. Da mesma forma que verbos como correr, os verbos de processos corporais também não possibilitam a formação de uma variante causativa, conforme (3):
a. A criança respirou.
b. Maria espirrou.
c. *A mãe respirou a criança.
d. *João espirrou Maria.

Já os verbos de emissão são aqueles que denotam eventos que envolvem a emissão de alguma substância ou estímulo característico do participante (p. ex., luz, som, etc.). Interessantemente, estes verbos apresentam um comportamento heterogêneo em relação ao processo de causativização: enquanto verbos como reluzir e chiar não possibilitam a variante causativa (cf. $(5 \mathrm{a}, \mathrm{b})$ ), verbos como ressoar e badalar são compatíveis com uma causação externa (cf. 5c, d)).
a. A lâmpada reluziu.
b. A chaleira chiou.
c. O tambor ressoou.
d. O sino badalou.
a. *O rapaz reluziu a lâmpada.
b. ${ }^{*} \mathrm{O}$ fogo chiou a chaleira.
c. O músico ressoou o tambor.
d. O padre badalou o sino.

Neste artigo, apresentarei uma proposta para o tratamento dos verbos dinâmicos monoargumentais no português brasileiro que dá conta dos fatos expressos acima, sob a luz da Semântica Conceitual (JACKENDOFF, 1983; 1990; 2002). Mais especificamente, com base em Levin \& Rappaport Hovav (1992, 1995), argumentarei que as noções de causação interna e controle são cruciais para a definição dos verbos que participam ou não do processo de causativização. Conforme essa proposta, os verbos que denotam eventos causados internamente, marcados com o traço [+causação interna], não participam do processo de causativização. Somente verbos que denotam eventos não marcados para o tipo de causação seriam visíveis a esse processo, o que explicaria o contraste acima. Além disso, diferentemente de Jackendoff (1990), argumentarei que o predicado MOVE está envolvido somente na representação de eventos monoargumentais, dinâmicos e não necessariamente controlados pelo participante, independentemente do tipo de causação especificada pela raiz do verbo. Seguindo Pinker (1989) e Rappaport Hovav \& Levin (1998, 2010), defenderei que verbos dinâmicos monoargumentais que acarretam controle do participante são representados pelo predicado primitivo $\mathrm{ACT}{ }^{2}$

Para tanto, na seção 2, iniciarei a discussão apresentando os principais problemas da proposta de Jackendoff (1990) para o tratamento dos verbos de

\footnotetext{
${ }^{2}$ Versões preliminares de algumas das ideias defendidas no presente artigo foram apresentadas anteriormente em Menuzzi \& Ribeiro (2011) e Ribeiro (2014).
} 
modo de movimento, a qual o autor sugere que pode ser estendida para outras classes de verbos monoargumentais. O foco estará não somente no fato de que Jackendoff não lida com a causativização desses verbos, mas também na distinção estabelecida pelo autor entre verbos como correr e rolar, representados por GO, e verbos como dançar e pular, representados por MOVE. Na seção 3, discutirei algumas análises clássicas das noções de controle, causação interna e eventos acionais na semântica lexical, as quais servirão como base para a proposta apresentada neste trabalho. Por fim, na seção 4, apresentarei minha proposta para a representação léxico-conceitual dos verbos dinâmicos monoargumentais, que envolve os predicados primitivos MOVE e ACT, bem como os traços de controle e causação interna. Essa proposta pretende dar conta da representação léxico-conceitual das subclasses de verbos dinâmicos monoargumentais no português brasileiro.

\section{O TRATAMENTO DE JACKENDOFF (1990) PARA OS VERBOS DE MODO DE MOVIMENTO}

Jackendoff (1990) propõe que os verbos de modo de movimento sejam representados pela função monoargumental MOVE, que representa uma inovação em relação à teoria proposta em Jackendoff (1983). Para o autor, verbos como spin ("girar") e dance ("dançar") denotam apenas o movimento do participante, sem nenhuma implicação sobre a sua localização ou deslocamento ao longo de uma trajetória, portanto seriam instâncias dessa função:

$$
\begin{aligned}
& \text { a. Mary danced/spun (for hours). } \\
& \text { 'Maria dançou/girou (por horas)' } \\
& \text { b. }\left[\begin{array}{l}
\text { MOVE ([ [hing MARY ]) } \\
\text { Event } A F F_{+\mathrm{vol}}([\mathrm{MARY}],)
\end{array}\right]
\end{aligned}
$$

Por outro lado, o autor assume que verbos de modo de movimento como roll ("rolar") e run ("correr") lexicalizam uma trajetória - ainda que esta possa ser implícita -, e por isso são representados pelo predicado GO. Por exemplo, Jackendoff estipula na entrada lexical do verbo run a opcionalidade do sintagma preposicional (cf. (7c)), assumindo que é parte do significado do verbo que a entidade envolvida na eventualidade percorreu uma trajetória, mesmo quando o SP não é realizado sintaticamente.

$$
\begin{aligned}
& \text { a. John ran into the room. } \\
& \text { 'João correu para dentro da sala' } \\
& \text { b. John ran (for hours). } \\
& \text { 'João correu (por horas)' }
\end{aligned}
$$

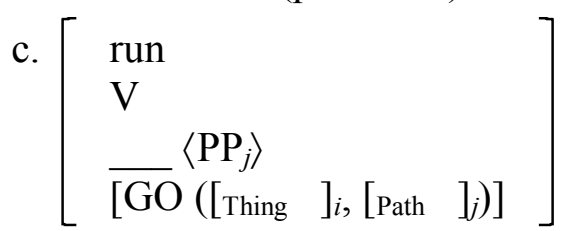


Apesar de essa análise descrever adequadamente alguns elementos do significado dos verbos de modo de movimento, argumentarei aqui que o tratamento proposto por Jackendoff para essa classe enfrenta um problema crucial. A proposta do autor não considera o contraste em (1)-(2), entre verbos de modo de movimento controlado pelo participante (p. ex., correr, caminhar e dançar) e não controlado pelo participante (p. ex., rolar, quicar e girar). Conforme vimos, ao menos em uma primeira análise, somente os verbos de modo de movimento não controlados estão sujeitos a um processo lexical semelhante à alternância causativa; isto é, permitem a formação de uma variante transitiva, com a incorporação de uma causa externa ao evento. Esse contraste sugere que a noção de controle é relevante para o comportamento gramatical dos verbos de modo de movimento.

A hipótese que defenderei neste artigo, contra Jackendoff (1990), é a de que os verbos de modo de movimento lexicalizam apenas maneira, sem especificar nenhuma informação em relação à trajetória. Ao contrário de verbos de movimento direcionais, como entrar e sair, verbos de modo de movimento como correr e caminhar não acarretam deslocamento ao longo de uma trajetória, como defende Jackendoff; antes, esta parece ser apenas uma inferência pragmática, que pode ser cancelada, como ilustram os exemplos abaixo:

(8) a. Paulo correu por um bom tempo, mas não saiu do lugar.

b. Maria caminhou por horas no mesmo lugar.

a. \#O aluno entrou na sala, mas não saiu do lugar.

b. \#Maria saiu de casa, mas ficou no mesmo lugar.

As sentenças em (8) são perfeitamente aceitáveis, por exemplo, em um contexto em que os participantes estão se exercitando em uma esteira, ou mesmo no caso de se movimentarem em uma superfície extremamente escorregadia, como uma pista de gelo. O mesmo não ocorre com verbos de movimento direcionais, como observamos em (9), uma vez que esses verbos acarretam o deslocamento ao longo de uma trajetória.

Estabelecida a possibilidade de uma análise unificada para os verbos de modo de movimento como verbos de maneira, na seção seguinte, farei uma breve revisão da literatura sobre as noções de controle e causação interna e externa em semântica lexical, as quais serão essenciais para a proposta de representação dos verbos dinâmicos monoargumentais que apresentarei na seção 4 . 


\section{ALGUMAS ANÁLISES DAS NOÇÕES DE CONTROLE E CAUSAÇÃO INTERNA EM SEMÂNTICA LEXICAL}

\subsection{Pinker (1989): a função ACT}

Pinker (1989) propõe que eventos acionais envolvem a função ACT, conforme observamos na representação do verbo yawn ("bocejar") do inglês em (10):

(10) yawn:

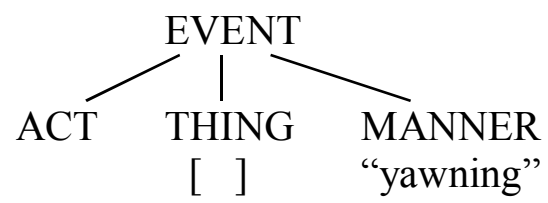

(PINKER, 1989, p. 193)

Conforme o exemplo acima, o predicado ACT toma como argumento um participante do tipo semântico THING e especifica uma maneira de realização da ação, representada por MANNER. Na teoria de Pinker, a representação de maneira serve como um indicador para a representação cognitiva das propriedades físicas e geométricas do modo de ação.

$\mathrm{O}$ autor assume que tanto ações não necessariamente controladas, como bocejar, como ações controladas, como beijar, por exemplo, são representadas pelo mesmo predicado ACT. No entanto, o autor reconhece que eventos envolvendo ACT são prototipicamente interpretados como volicionais. De modo a dar conta desse fato, Pinker propõe uma especificação das funções primitivas em sua teoria por meio dos traços [ \pm dinâmico] e [ \pm controle]. Nesse sistema, o traço [ \pm dinâmico] determina se a eventualidade se trata de um evento ou de um estado. Por sua vez, o traço [ \pm controle] define se o primeiro argumento de um predicado é humano e possui o controle da eventualidade. Dessa maneira, no caso não marcado, o predicado ACT seria [+dinâmico] e [+controle], o que definiria os verbos representados por esse predicado como causados internamente.

O predicado primitivo ACT, conforme definido por Pinker, passou a ser utilizado amplamente na literatura para a representação de eventos acionais. $\mathrm{Na}$ seção seguinte, discutirei brevemente a proposta de Rappaport Hovav \& Levin $(1998,2010)$ para a representação dos chamados pelas autoras de verbos de maneira, que lança mão do predicado ACT, assim como de uma noção crucial para a compreensão de fenômenos como a causativização: a noção de "raiz" nas representações léxico-semânticas dos verbos.

\subsection{Rappaport Hovav \& Levin $(1998,2010)$ : ACT e a noção de raiz}

Na mesma linha do trabalho de Pinker, Rappaport Hovav \& Levin (1998, 2010) propõem que verbos de maneira como correr, rir e bocejar, por exemplo, sejam representados pelo predicado ACT. Entretanto, as autoras desenvolvem uma teoria mais articulada das representações léxico-semânticas desses verbos. 
Nessa teoria, o componente idiossincrático do verbo, ou seja, sua "raiz", e o componente estrutural, que representa o tipo de evento, possuem papéis diferentes: o componente estrutural é composto por funções semânticas primitivas, e o idiossincrático entra como modificador ou argumento dessas funções. Especificamente, as autoras formulam um conjunto de regras de realização canônicas que expressam as formas como a categoria ontológica da raiz (p. ex., maneira, instrumento, estado resultante, etc.) pode se integrar à estrutura de eventos básica do verbo. Vejamos alguns exemplos abaixo:

$$
\begin{aligned}
& \text { maneira } \rightarrow\left[x \mathrm{ACT}_{<M A N N E R>}\right] \\
& (\mathrm{p} . \text { ex., correr, varrer, rir, etc.) }
\end{aligned}
$$

estado causado externamente; ou seja, resultado $\rightarrow$

[ [ $x$ ACT ] CAUSE [ $y$ BECOME <RESULT-STATE $>$ ]]

(p. ex., quebrar, secar, derreter, etc.)

(Adaptado de RAPPAPORT HOVAV; LEVIN, 2010, p. 24)

Como observamos acima, as raízes podem tanto ser argumentos na representação dos eventos (cf. (12)), como podem ser "modificadores" de predicados primitivos (cf. (11)). Para as autoras, os verbos não estativos nas línguas dividem-se em duas grandes classes, de acordo com o tipo de sua raiz: verbos de maneira, que seriam verbos de causação interna, e verbos de resultado, que seriam verbos de causação externa. As raízes de maneira seriam aquelas que modificam o predicado ACT, enquanto as de resultado seriam argumentos do predicado BECOME.

No que diz respeito à representação dos verbos de maneira, de acordo com a teoria proposta por Rappaport Hovav \& Levin, verbos de atividade como correr, rir e varrer, por exemplo, são representados pelo predicado ACT, conforme ilustrado em (11). As autoras não discutem em detalhe qual seria a semântica exata desse predicado primitivo; contudo, os exemplos em (11) sugerem que ACT está envolvido tanto em eventos volicionais como não volicionais, seguindo a linha da proposta de Pinker (1989). De modo a caracterizar de maneira mais precisa a natureza das ações volicionais, discutirei na seção seguinte a proposta de Jackendoff (2007) para o tratamento desses eventos na Semântica Conceitual.

\subsection{Jackendoff (2007) e o tratamento das ações volicionais}

Jackendoff (2007) desenvolve um estudo sobre a intencionalidade na estrutura conceitual; isto é, sobre como os falantes conceitualizam situações em que se pode atribuir intenção a um participante. De modo a caracterizar precisamente o que entende como uma ação volicional, Jackendoff discute a hierarquização das eventualidades, propondo que eventos e ações sejam incluídos em uma hierarquia mais ampla de situações. $\mathrm{O}$ autor utiliza o teste proposto para a identificação de Atores em Jackendoff (1990) para diferenciar ações como um 
subtipo de evento, em que se pode dizer que o participante do evento "faz alguma coisa", conforme mostram os exemplos abaixo.

Ações:

a. O que Neymar fez foi marcar um gol.

b. O que os EUA fizeram foi invadir o Iraque.

(14) Eventos não acionais:

a. ${ }^{*} \mathrm{O}$ que Paulo fez foi receber uma carta.

b. *O que João fez foi ser acertado por uma pedra.

(Adaptado de JACKENDOFF, 2007, p. 246)

Contudo, Jackendoff chama a atenção para o fato de que nem todo Ator, de acordo com sua proposta, realiza uma ação volicional, uma vez que o teste proposto também captura (ao menos em inglês) ações não intencionais e Atores não animados, conforme podemos observar em (15) abaixo.

a. What Bill accidentally did was roll down the hill.

?O que Bill acidentalmente fez foi rolar montanha abaixo'

b. What the rock did was roll down the hill.

'?O que a pedra fez foi rolar montanha abaixo'

(JACKENDOFF, 2007, p. 246)

Apesar de os exemplos em (15) parecerem menos aceitáveis em português, conforme discutirei adiante, o ponto aqui é que a noção de intencionalidade só entra em jogo no caso de um Ator animado. Por exemplo, não é possível utilizar o advérbio intencionalmente em sentenças com sujeito não animado (cf. *A pedra rolou intencionalmente montanha abaixo). Isso faz com que Jackendoff defina um subtipo de ação, ao qual chama de "ação animada", o que resulta na seguinte ontologia:

Situações $\supset$ Eventos $\supset$ Ações $\supset$ Ações animadas

De acordo com Jackendoff, o critério para definir se um evento pode ser construído conceitualmente como uma ação, ou seja, como "fazer algo", é o teste proposto em (13)-(14). Essa distinção é relevante para a análise proposta pelo autor para os verbos de atitude proposicional como acreditar, imaginar, pretender e planejar, por exemplo. Conforme essa proposta, verbos como acreditar denotariam "atitudes situacionais", uma vez que uma crença pode ser adotada em relação a qualquer situação, seja esta um estado ou evento (p. ex., João acreditava que Paulo havia saído/que Paulo era alto). Por outro lado, verbos como pretender denotariam "atitudes acionais", já que, ao menos nos casos em que o complemento do verbo é uma sentença infinitiva, um indivíduo só pode ter intenção em relação a uma ação na qual ele próprio é o Ator (p. ex., João pretendia passar na prova/*ser alto).

A formalização proposta por Jackendoff para a representação dessas atitudes na estrutura conceitual assume que a atitude envolvida em verbos como acreditar e pretender tem a mesma natureza, ou seja, é uma atitude de "comprometimento", a qual ele define por meio da função COM. A principal 
diferença, conforme vimos acima, é que verbos como acreditar tomam como complementos qualquer tipo de situação, enquanto verbos como pretender necessitam que seu complemento seja uma ação - isto é, nos termos do autor, possua o traço [+Action]. Assim, um verbo como acreditar teria a estrutura léxico-conceitual em (17a), enquanto o verbo pretender teria a representação em (17b) abaixo.

a. $\mathrm{X}$ acredita que $\mathrm{P}$.

[X COM [Situation, -Action $\mathrm{P}]]$

b. $\mathrm{X}$ pretende agir.

$\left[\mathrm{X}^{\alpha} \mathrm{COM}[\right.$ Situation, +Action $\left.\alpha \mathrm{ACT}]\right]$

(Adaptado de JACKENDOFF, 2007, p. 260)

Com essa formalização, Jackendoff estabelece as ferramentas necessárias para tentar explicar o fato de que eventos acionais são preferencialmente concebidos pelos falantes como volicionais. Conforme o autor, apesar de frequentemente os falantes cometerem erros, atribuindo intenção a quem não a tem, essa hipótese faz parte do modo como conceitualizamos noções sobre o que ocorre na mente dos outros falantes. Jackendoff propõe uma formalização dessa hipótese, por meio da regra de inferência em (18):

$$
[\mathrm{X} \mathrm{ACT}] \Rightarrow_{\text {default }}\left[\begin{array}{l}
\mathrm{X}^{\alpha} \mathrm{ACT} \\
{[\mathrm{FROM}[\alpha \mathrm{COM}[\text { Situation, +Action } \beta]]]}
\end{array}\right]
$$

(JACKENDOFF, 2007, p. 265)

Essa regra, a qual chamarei de "regra de inferência intencional", define que, a não ser que haja evidência ao contrário, ações são interpretadas como volicionais. ${ }^{3}$ Jackendoff argumenta que a regra em (18) possibilita uma análise interessante para a ambiguidade relativa à interpretação volicional do sujeito de verbos como rolar ou deslizar (cf. João rolou/deslizou montanha abaixo (intencionalmente/sem querer)). Ao invés de assumir que esses verbos são polissêmicos, possuindo um traço opcional de volição em suas entradas lexicais, Jackendoff propõe que a regra em (18) seja parte dos princípios gerais de interpretação das sentenças. Dessa maneira, como explica o autor, na presença de um sujeito animado, todos os verbos de ação (portanto, todos os verbos de "ação animada") automaticamente possibilitariam uma interpretação volicional, sem a necessidade de especificação no léxico. Na seção seguinte, elaborarei minha proposta para a representação dos verbos dinâmicos monoargumentais, a qual levará em conta a regra de inferência intencional de Jackendoff.

\footnotetext{
${ }^{3}$ Conforme Jackendoff, a função FROM em (18) marca seu argumento como Causa (cf. João morreu de fome.) (JACKENDOFF, 2007, p. 264). Neste caso específico, a Causa se caracteriza como a intenção de $\alpha$ de realizar uma determinada ação $\beta$.
} 


\section{A REPRESENTAÇÃO LÉXICO-CONCEITUAL DOS VERBOS DINÂMICOS MONOARGUMENTAIS}

\subsection{Os verbos de modo de movimento e a distinção entre MOVE e ACT}

Nesta seção, apresentarei uma proposta para a representação léxicoconceitual dos verbos dinâmicos monoargumentais no português brasileiro sob a luz da Semântica Conceitual (JACKENDOFF, 1983; 1990; 2002). Essa proposta busca lidar com o comportamento gramatical desses verbos em relação à possibilidade ou não de participarem de um processo lexical de causativização. Parto do pressuposto de que a noção de movimento de uma entidade, isto é, de dinamicidade, é uma noção básica na estrutura conceitual. A partir desse pressuposto, examinarei de que maneira as noções semânticas discutidas nas seções anteriores, como controle e causação interna, interagem com a noção básica de dinamicidade na constituição do significado dos verbos monoargumentais.

A primeira subclasse dos verbos dinâmicos monoargumentais que tratarei é a dos verbos de modo de movimento. Inicialmente, gostaria de propor que o predicado primitivo MOVE seja responsável simplesmente pela codificação na estrutura conceitual da noção básica de dinamicidade de uma entidade. Conforme especificado em (19) abaixo, assumo que MOVE é um predicado monoargumental, modificado por uma raiz de maneira (cf. RAPPAPORT HOVAV; LEVIN, 1998, 2010), e que acarreta lexicalmente que o participante é dinâmico - isto é, apresenta movimento. Nessa análise, eventos de modo de movimento que não acarretam o deslocamento do participante ao longo de uma trajetória são instâncias desse predicado, como é o caso dos verbos da classe de rolar:

a. A bola rolou/girou/quicou.

b. $\left[\begin{array}{l}\text { MOVE }([\text { Thing BOLA }]) \\ \text { Event }[\text { Manner ROLAR/GIRAR/QUICAR }]\end{array}\right]$

$\rightarrow$ O evento é [+dinâmico]

Como podemos observar na representação em (19b), a noção de raiz proposta por Rappaport Hovav \& Levin encontra-se incorporada à representação do predicado MOVE. Dessa maneira, assumo que raízes de maneira também podem modificar o predicado MOVE, e não somente o predicado ACT, o que não era previsto inicialmente pela proposta das autoras.

Seguindo a proposta de Levin \& Rappaport Hovav (1995), assumo que a distinção entre eventos de causação externa e eventos de causação interna é relevante para a definição da participação dos verbos em processos de causativização. Devido ao fato de o predicado MOVE não ser especificado para o 
tipo de causação envolvida no evento, proponho que os eventos que envolvem esse predicado sejam mais facilmente concebíveis como tendo uma causa externa:

(20) a. A bola rolou/girou/quicou.

b. O jogador rolou/girou/quicou a bola.

(21) a. A bandeira tremulou/sacudiu/balançou.

b. O vento tremulou/sacudiu/balançou a bandeira.

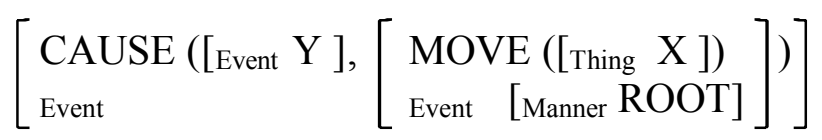

Por não especificar o tipo de causação, a estrutura de eventos de verbos como os em (20)-(21), envolvendo MOVE, seria visível ao processo lexical de causação, que gera estruturas como (22), em que dois subeventos são relacionados por meio do predicado CAUSE, sendo o primeiro a Causa e o segundo o Efeito.

Por sua vez, proponho que eventos que são concebidos conceitualmente como ações controladas pelo participante sejam representados por um predicado primitivo específico, o predicado ACT. Especificamente, seguindo a linha das propostas de Pinker (1989) e Rappaport Hovav \& Levin (1998, 2010), proponho que os eventos de modo de movimento causados internamente, em que o participante possui controle sobre a ação, sejam instâncias do predicado monoargumental ACT, e não de MOVE. Como podemos observar em (23) abaixo, ACT acarreta lexicalmente que o evento é dinâmico, causado internamente e controlado pelo participante. Com essa análise, verbos de modo de movimento da classe de correr seriam instâncias do predicado ACT:

a. João correu/caminhou/dançou.

b. ACT ([Thing JOÃO ])

Event [Manner CORRER/CAMINHAR/DANÇAR]

$\rightarrow$ O evento é [+dinâmico], [+causação interna] e [+controle]

Da mesma forma que os verbos representados por MOVE, os verbos representados por ACT não acarretam o deslocamento do participante ao longo de uma trajetória. Adoto aqui o teste empírico proposto por Jackendoff (2007) para identificar eventos que são concebidos como ações - ou seja, "O que X fez foi..." - para definir os eventos envolvendo ACT. Com base nesse teste, podemos identificar o contraste entre os eventos em (24a) e (24b):

(24) a. O que João fez foi correr/caminhar/dançar alguns minutos.

b. ?O que a bola fez foi rolar/girar/deslizar alguns minutos.

Conforme (24b), no caso de sujeitos não animados, o teste da clivada resulta em sentenças menos aceitáveis no português, em contraste com o inglês, como vimos na seção anterior (ver exemplos $(15 a, b)$ ). Ao menos em português, $o$ teste sugere que eventos de modo de movimento como os em (24b), além de não 
acarretarem controle do participante, não são conceitualizados como ações, justificando, dessa maneira, a análise com MOVE.

Segundo a definição em (23b), os verbos representados por ACT são especificados como causados internamente. Conforme vimos, eventos com causação interna são provocados por alguma característica inerente do participante do evento e, portanto, não são compatíveis com um causador externo. Com isso, verbos representados por ACT não são visíveis ao processo de causativização:

a. *Maria correu/caminhou/nadou João.

b. $*\left[\begin{array}{l}\left.\text { CAUSE }\left([\text { Event } \mathrm{Y}],\left[\begin{array}{l}\text { ACT }([\text { Thing X }]) \\ \text { Event }\end{array}\right]\right)\right] \\ \text { Event }[\text { Manner ROOT }]\end{array}\right]$

Crucialmente, a representação léxico-semântica proposta para os verbos de modo de movimento com MOVE em (19b) especifica que a raiz desses verbos expressa um modificador de maneira aplicado a um predicado de movimento primitivo - da mesma forma que (23b), com a única diferença de estes eventos serem considerados ações controladas e causadas internamente e envolverem, portanto, o predicado ACT. Ao mesmo tempo, por MOVE ser um predicado primitivo que não é especificado para causação interna inerente, (19b) permite que verbos como rolar e girar, por exemplo, sejam distinguíveis dos verbos de ACT com respeito a processos de causação; assim, verbos com MOVE e com ACT podem ser tratados de modo diferente por processos lexicais como a causativização em português.

Note que o traço [+volicional] não faz parte da definição do predicado ACT: seguindo Jackendoff (2007), suponho que a noção de volição é uma inferência de ações controladas pelo participante. Dessa maneira, no caso de eventos envolvendo ACT, assumo que se aplica a "regra de inferência intencional" (adaptada de JACKENDOFF, 2007, p. 265):

$$
\begin{aligned}
& {[\operatorname{ACT}([\text { Thing } X])] \Rightarrow_{\text {default }}\left[\begin{array}{l}
\operatorname{ACT}\left([\text { Thing X }]^{\alpha}\right) \\
{[\text { FROM }[\alpha \operatorname{COM}[\text { Situation, }+ \text { Action } \beta]]}
\end{array}\right]} \\
& \rightarrow \text { O evento é }[+ \text { dinâmico }],[+ \text { causação interna }],[+ \text { controle }] \text { e }[+ \text { volicional }]
\end{aligned}
$$

Entretanto, ainda resta uma questão crucial: como lidar com o fato bastante conhecido na literatura de que alguns verbos de modo de movimento do tipo de rolar são ambíguos entre uma leitura "volicional" e "não volicional"? A alternativa de análise adotada aqui será propor uma regra de inferência, nos moldes da "regra de inferência intencional" de Jackendoff (2007), a qual determina que, no caso de um participante [+animado], um evento de modo de movimento (MOVE) é interpretado como uma ação (ACT):

[MOVE ([Thing X ])] $\Rightarrow_{\text {default }}[$ ACT ([Thing X ])], se X for [+animado] $\rightarrow$ O evento é [+dinâmico], [+causação interna], [+controle] 
Uma vez aplicada essa regra, torna-se possível a aplicação também da "regra de inferência intencional", que atua por default em todos os eventos envolvendo ACT, ainda que por inferência. Isso explicaria o fato de que, na presença de um participante animado, verbos do tipo de rolar têm um comportamento similar ao dos verbos envolvendo ACT:

(28) a. João rolou/girou/deslizou no chão intencionalmente.

b. O que João fez foi rolar/girar/deslizar no chão intencionalmente.

Como podemos observar em (28b), o teste com a clivada mostra que esses eventos são interpretados como ações; porém, esse comportamento resulta da aplicação das regras de inferência discutidas acima. Em outras palavras, a alternância no significado de alguns verbos do tipo de rolar para uma interpretação de controle e causação interna não constitui um tipo de polissemia lexical; antes, é resultado da subespecificação do predicado MOVE quanto ao tipo de causação envolvida no evento. Por exemplo, não há duas entradas lexicais para o verbo rolar, mas sim a possibilidade de o evento denotado por esse verbo, na presença de um participante animado, ser interpretado, por inferência, como uma ação. Uma indicação nesse sentido é o fato de o significado especificado pela raiz de um verbo como rolar ser exatamente o mesmo (ou seja, o modo de se movimentar "rolando") tanto na interpretação de ação volitiva como na de movimento causado externamente. De acordo com a presente proposta, portanto, ações são um subtipo específico de movimento, que é a noção mais básica na estrutura conceitual.

\subsection{Estendendo a análise para os verbos de processos corporais e para os verbos de emissão}

Jackendoff (1990) sugere brevemente que outros verbos monoargumentais do inglês, como laugh ("rir") e sneeze ("espirrar"), também poderiam pertencer à classe dos verbos representados por MOVE. No entanto, a proposta apresentada na seção anterior possibilita uma alternativa mais interessante de análise para essa classe verbal. Conforme observamos na introdução do artigo, os verbos de processos corporais não possibilitam a formação de uma variante causativa, o que indica que denotam eventos causados internamente.
a. Paulo soluçou/arrotou/bocejou/tremeu.
b. *Maria soluçou/arrotou/bocejou/tremeu Paulo.

No entanto, ao contrário dos verbos da classe de correr, a aplicação do teste para a identificação de ações indica que os verbos de processos corporais têm um comportamento gramatical intermediário, como podemos observar em (30)-(31):

?O que o Paulo fez foi rir/espirrar/dormir. 
(31) a. O que o Paulo faz quando tá muito frio?

b. Ele corre/caminha.

c. ?Ele espirra/tosse.

Em (30), a aplicação do teste da clivada gera sentenças menos aceitáveis com verbos como rir, espirrar e dormir, em contraste com verbos como correr e caminhar, uma vez que esses verbos denotam eventos concebidos como não necessariamente controlados pelo participante - ou seja, concebidos normalmente como processos corporais involuntários. O contexto de pergunta e resposta em (31) torna mais claro o contraste entre essas classes verbais: enquanto os eventos denotados por correr e caminhar são facilmente conceitualizados como ações que Paulo realiza quando está muito frio (cf. (31b)), a utilização de verbos como espirrar e tossir gera sentenças menos aceitáveis no mesmo contexto (cf. 31c). Com base nesses exemplos, concluo que, apesar de denotarem eventos dinâmicos causados internamente, os verbos de processos corporais não são especificados para a noção de controle, o que os impede de serem representados pelo predicado ACT. Proponho que esses verbos sejam instâncias do predicado MOVE, mas que sejam marcados com o diacrítico [+causação interna], ou [+CI], para indicar que o evento é causado por uma propriedade inerente do participante:

a. Maria bocejou/dormiu/roncou.

$$
\begin{aligned}
& \text { b. }\left[\begin{array}{l}
\mathrm{MOVE}^{+\mathrm{CI}}([\text { Thing MARIA }]) \\
\text { Event [Manner BOCEJAR/DORMIR/RONCAR] }
\end{array}\right] \\
& \rightarrow \text { O evento é [+dinâmico] e [+causação interna] }
\end{aligned}
$$

Conforme (32), MOVE ${ }^{+\mathrm{CI}}$ acarreta lexicalmente que o evento é dinâmico e tem causação interna. Esse fato explica por que, assim como os verbos da classe de correr, esses verbos não são visíveis ao processo de causativização. Por outro lado, por não serem especificados para controle, não são facilmente conceitualizados como ações na estrutura conceitual.

No entanto, assim como os outros verbos representados por MOVE, como rolar e girar, os verbos de processos corporais também estão sujeitos à aplicação das regras de inferência em (26) e (27), uma vez que os participantes desses eventos são, de modo geral, animados. Isso daria conta do fato de que os eventos denotados por esses verbos são compatíveis com uma interpretação em que o participante tem controle da ação:

a. João riu/bocejou/chorou intencionalmente.

b. João parou de rir/bocejar/chorar após o pedido de Maria

Por sua vez, os verbos de emissão, conforme vimos na introdução deste artigo (cf. (4)-(5)), apresentam um comportamento heterogêneo em relação à participação no processo de causativização. Em um estudo de corpus sobre os verbos de emissão de som, Levin, Song \& Atkins (1997) mostram que a distinção entre causação interna e externa é relevante para a possibilidade ou não de causativização de verbos dessa classe em inglês. De acordo com os autores, 
verbos de emissão que descrevem sons produzidos internamente pelo emissor como chiar e gemer, por exemplo - são conceitualizados como causados internamente. Por outro lado, verbos que descrevem sons produzidos de maneira externa ao emissor - por exemplo, estalar e soar - são conceitualizados como causados externamente. Portanto, seguindo Levin, Song \& Atkins, assumo que o comportamento gramatical desses verbos, relativo à causativização, pode ser explicado pelo tipo de causação envolvida no evento; nos termos da proposta desenvolvida na seção anterior, os verbos de emissão seriam verbos de MOVE, e a presença ou não do traço $[+\mathrm{CI}]$ seria responsável pela participação ou não desses verbos no processo de causativização:

a. A chaleira chiou/apitou/assobiou.

b. $\left[\begin{array}{l}\text { MOVE }^{+\mathrm{CI}}([\text { Thing CHALEIRA }]) \\ \text { Event }[\text { Manner CHIAR/APITAR/ASSOBIAR }]\end{array}\right]$

a. Os tambores soaram/ressoaram/bateram.

b. $\left[\begin{array}{l}\text { MOVE ([Thing TAMBORES }]) \\ \text { Event }[\text { Manner SOAR/RESSOAR/BATER }]\end{array}\right]$

Com essa análise, acredito ter apresentado um tratamento amplo para os verbos dinâmicos monoargumentais do português brasileiro, lidando adequadamente com o comportamento gramatical desses verbos em relação à participação ou não no processo lexical de causativização.

\section{CONSIDERAÇÕES FINAIS}

Neste artigo, foi apresentada uma proposta para a representação léxicoconceitual dos verbos dinâmicos monoargumentais que lida com o comportamento gramatical desses verbos em relação à sua participação no processo de causativização. De acordo com essa proposta, o predicado primitivo MOVE representa a noção básica de dinamismo na estrutura conceitual, ao passo que os eventos conceitualizados como ações controladas pelos participantes são representados pela função ACT, que consiste em um subtipo mais específico de MOVE. Com base em Levin \& Rappaport Hovav (1995), avaliei o papel da noção de causação interna na determinação dos verbos que participam do processo de causativização em português. A conclusão foi a de que essa noção é ortogonal à classificação de eventos de modo de movimento (MOVE) e ações (ACT), sendo melhor tratada como um traço modificador dessas funções primitivas.

Seguindo Jackendoff (2007), defendi que a noção de volição decorre de uma regra de inferência que faz parte do sistema de interpretação das sentenças. No mesmo sentido, propus uma regra de inferência que estabelece que eventos envolvendo MOVE sejam interpretados como ações na presença de um participante animado. Por meio dessas regras de inferência, pode-se lidar com o fato conhecido de que verbos como rolar alternam entre uma leitura 
"volicional" e "não volicional", sem precisar postular duas entradas lexicais para esses verbos.

\section{REFERÊNCIAS}

JACKENDOFF, R. Semantics and Cognition. Cambridge, MA: MIT Press, 1983. . Semantic Structures. Cambridge, MA: MIT Press, 1990.

. Foundations of Language: Brain, Meaning, Grammar, Evolution. Oxford: Oxford University Press, 2002.

. Language, Consciousness, Culture: Essays on Mental Structure. Cambridge, MA: MIT Press, 2007.

LEVIN, B. English verb classes and alternations. Chicago: University of Chicago Press, 1993.

LEVIN, B.; RAPPAPORT HOVAV, M. Unaccusativity: At the Syntax-Lexical Semantics Interface. Cambridge, MA: MIT Press, 1995.

LEVIN, B.; SONG, G.; ATKINS, B. Making Sense of Corpus Data: A Case Study of Verbs of Sound. International Journal of Corpus Linguistics. Amsterdam: John Benjamins Publishing Company, n. 2, 1997, p. 23-64.

MENUZZI, S.; RIBEIRO, P. A representação léxico-semântica de alguns tipos de verbos monoargumentais. Cadernos do IL. Porto Alegre, v. 41, 2011, p. 23-45.

PINKER, S. Learnability and cognition. Cambridge, MA: MIT Press, 1989.

RAPPAPORT HOVAV, M.; LEVIN, B. What to do with theta-roles. In: WILKINS, W. (ed.). Syntax and Semantics 21: Thematic relations. Nova York: Academic Press, 1988, p. 7-36.

. Building Verb Meanings. In: BUTT, M.; GEUDER, W. (eds.). The Projection of Arguments: Lexical and Compositional Factors. Stanford: CSLI Publications, 1998, p. 97-134.

.Reflections on Manner/Result Complementarity. In: DORON, E.; RAPPAPORT HOVAV, M.; SICHEL, I. (eds.). Syntax, Lexical Semantics, and Event Structure. Oxford: Oxford University Press, 2010, p. 21-38.

RIBEIRO, P. Revisitando a Semântica Conceitual de Jackendoff: um estudo sobre a semântica verbal no PB sob a perspectiva da Hipótese Locacional. Porto 
Alegre, RS: 2014. 186 f. Tese (Doutorado em Letras), Instituto de Letras, UFRGS, Porto Alegre.

Pablo Nunes Ribeiro PabloNRibeiro@yahoo.com.br

Recebido em: 12 jan. 2018 Aceito em: 12 mar. 2018 Publicado em: 1 out. 2018 